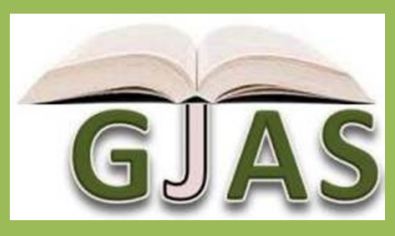

\title{
An Evaluation of 'Vinasse' (Bio-Ethanol Effluent) and Vermicompost as Soil Amendments for Cash Crop Production
}

\section{Clairmont Clementson*, Bibi Nariefa Abrahim, Oudho Homenauth $^{2}$, Vickram Persaud ${ }^{3}$}

\author{
National Agricultural Research and Extension Institute, Mon Repos, East Coast Demerara, \\ Guyana \\ E-mails: ${ }^{1}$ narie_abrahim@ hotmail.com, ${ }^{2}$ oudhohomenauth@ gmail.com, \\ vickram05@yahoo.com
}

\section{ARTICLE INFO}

Article No.: 092816148

DOI: 10.15580/GJAS.2016.9.092816148

Submitted: $28 / 09 / 2016$

Accepted: 05/10/2016

Published: 14/10/2016

${ }^{*}$ Corresponding Author

Clairmont Clementson

E-mail:kemba_cc@yahoo.com

Keywords:

vinasse, vermicompost, NPK, soil amendments, cash crop, fertilizers
The indiscriminate application of various inorganic fertilizers has triggered many soil, water and health issues around the world. Due to the extent of these concerns, various forms of organic fertilizers have since been explored. This study sought to establish the suitability of two organic composites (vinasse and vermicompost) as fertilizers in cash crop production. The crops selected were leafy vegetables from the Class of Magnoliopsida and included Brassica rappa spp. Chinesis (pakchoi), Lactuca sativa (lettuce) and Brassica oleracea var. capitata (cabbage). The response of these crops to four fertilization regimes (control - no fertilizers, vermicompost, vinasse and NPK) were monitored. Upon harvesting, data regarding weight of plants and number of leaves were recorded and analyzed. There was a $35.8 \%, 15.6 \%$ and a $20.7 \%$ greater yield of lettuce, pakchoi and cabbage, when vinasse was used as the fertilizer, as compared with NPK. With vermicompost, there were $19.5 \%$ and $5.2 \%$ higher yields for lettuce and cabbage with a $\mathbf{1 5 . 6 \%}$ reduction of yield for pakchoi as compared with NPK. Considering the increased yield demonstrated from this study coupled with the environmental, soil and crop nutrient benefits posited by other researchers, vinasse and vermicompost should be utilized as an organic replacement for inorganic fertilizers. 


\section{INTRODUCTION}

The 1950's green revolution provided an agricultural boom which was propelled largely by the introduction of chemical fertilizers. This intervention drastically improved food production and aided in the promotion of food security but the indiscriminate use of chemical fertilizers contributed immensely to environmental deterioration, depletion of fertile soils and the reduction in the nutritional values of the crops (Kumari et al., 2014; Savci, 2012).

Environmental degradation is a major concern that has received attention globally. Studies have indicated that organic fertilizers increase soil fertility by acting as a supplemental source of plant nutrients (Diacono and Montemurro, 2009). In addition to these direct effects on nutrient availability, organic materials can affect root growth, pests, and soil physical properties that in turn influence nutrient acquisition and plant growth (Palm et al., 1997). Organic fertilizers also increase soil aeration, moisture holding capacity and overall general soil structure (FAO, 2010).

Vinasse and vermicompost are two organic fertilizers that may serve as suitable replacements for chemical fertilizers. Vinasse is a byproduct from the distillation of fermented broth that produces ethanol. This aqueous solution although acidic is composed of both organic and inorganic compounds with high concentrations of potassium, calcium, magnesium, manganese, phosphorus and nitrogen (Abrahim et al., 2016). Due to its high nutrient content, vinasse is an attractive and environmentally acceptable soil amendment option for the agricultural industry. Studies in Brazil indicated that vinasse applied in appropriate volumes to sugar cane can partially or completely replace chemical fertilizers (Prado et al., 2013). With the development of the Bioethanol Plant here in Guyana, copious amounts of vinasse are being produced and it is crucial that an economic return be sought from this effluent. Most of the fertilizers used in Guyana are on short term crops (cash crops) and tests indicate vinasse is high in nutrients for these crops. This study explores the suitability of vinasse on short term leafy vegetables of high economic value produced locally.

Vermicompost a peat-like material that is rich in nitrogen $(23 \%)$, potassium (1.85-2.25\%) and phosphorus $(1.55-2.25 \%)$, micronutrients, plant growth hormones, enzymes and various soil microbes (Lazcano and Dominguez, 2011). It is derived from a mesophilic biotechnological process whereby earthworms convert fresh cow's manure, leaves and grass to a nutrient rich material, reducing its volume by forty to sixty percent (National Agricultural Research and Extension Institute, 2016). A typical earthworm weighs about 0.5 grams and eats an amount that is equivalent to its body weight and produces a cast equivalent to approximately fifty percent of the material it consumes in a day (Munroe, 2016). Studies such as Saranraj and Stella (2012) on various field crops, fruits and vegetables have shown that vermicompost helps to improve crop yield as it supplies balanced nutrients to plant roots and increases the organic matter content of the soil which helps to stimulate growth. This study will help to ascertain the practicability of using vermicompost on cash crop production.

Recognizing the effects chemical fertilizers poses on the environment, international organizations such as the United Nations Food and Agriculture Organization and the Inter-American Institute for Cooperation on Agriculture, along with countries such as India, China, Brazil and United States are trying to reduce, with the hope of someday eliminating the usage of these fertilizers. This study expands the focus on the use of organic fertilizers in Guyana by concentrating on two organic fertilizers that could be readily available in Guyana. With the abundant agricultural resources, vermicompost can be derived and with the establishment of the Albion Bioethanol Demonstration Plant, vinasse can be obtained.

The crops were selected based on their similarities (leafy vegetables from the Class of Magnoliopsida) and high economic value in Guyana. These crops are: Brassica rappa spp. Chinesis (pakchoi), Lactuca sativa (lettuce) and Brassica oleracea var. capitata (cabbage). They are all short term, single harvest crops which have almost similar fertilization requirements. Hence, this study seeks to explore the possibility of using vinasse and vermicompost as a soil amendment in cash crop cultivation.

\section{RESEARCH OBJECTIVES}

The general aim of this study is to investigate the use of bioethanol effluent (vinasse) and vermicompost as fertilizers in cash crop production. The specific objectives are:

1. To evaluate the use of vinasse and vermicompost as a sources of organic fertilizers.

2. To compare the use of organic fertilizers (vinasse and vermicompost) versus chemical fertilizer (NPK fertilizer).

3. To assess the potential of replacing chemical fertilizers with organic fertilizers for cash crop production in Guyana.

\section{RESEARCH METHODOLOGY}

This research was conducted under shaded conditions at National Agricultural Research and Extension Institute (NAREI) Farm, Mon Repos, Guyana. The crops were planted at different periods but were tested with the same experimental condition. For each crop, the 
experiments were done with four treatments; treatment 1 - control conditions with no fertilizer, treatment 2 vermicompost, treatment 3 - NPK 15:15:15 and treatment 4 - vinasse application. Each treatment was done in triplicates using the randomized complete block design. The trials were done with pakchoi, lettuce and cabbage respectively.

Samples of the vinasse and vermicompost were analyzed at the Guyana Sugar Corporation's (Guysuco) laboratory to determine their chemical properties. The soil and water conditions remained constant for all the tests. The $\mathrm{pH}$ of the vinasse and vermicompost were determined using a $\mathrm{pH}$ meter to be 3.94 and 5.28 respectively. The $\mathrm{pH}$ of the vinasse and vermicompost were increased to 6.5 using the liming requirement technique outlined by Kissel et al., 2007. The required amount of vinasse, vermicompost and NPK were calculated based on the application rate specified by Arafat and Yassen (2002), Central Research of Dryland Agriculture (2016) and Suphachai et al., 2006 respectively. The required amount of vinasse, vermicompost and NPK was determined to be $500 \mathrm{ml}$ per bed, $3.48 \mathrm{oz}$ and $6.77 \mathrm{~g}$ per plant respectively.

The pakchoi, lettuce and cabbage seedlings were transplanted March $11^{\text {th }} 2015$, May $20^{\text {th }} 2015$ and March $8^{\text {th }} 2016$ respectively and the fertilizers were applied two weeks after using the basal application method with the experimental design. The pakchoi and lettuce crops were harvested two weeks after fertilization, while the cabbage was harvested three (3) months after fertilization. For each trial, weights of each plant for various treatments were found using an electronic scale. Also, the number of leaves of the pakchoi and lettuce plants was counted and recorded; this was not done for cabbage given its folded nature. The data collected was analyzed statistically using the Statistix 9.0 Software. For each experiment, the Randomized Block Analysis of Variance and the LSD All Pairwise tests were done so as to determine if there was any significant difference between the weights and number of leaves of the plants between the four treatments.

\section{RESULTS}

Table 1: Showing the chemical analysis of vinasse and vermicompost used in the experiments

\begin{tabular}{|c|c|c|c|c|c|c|c|c|c|}
\hline Sample & $\mathbf{p H}$ & $\begin{array}{c}\mathbf{P} \\
(\mathbf{m g} / \mathbf{l})\end{array}$ & $\begin{array}{c}\text { Total N } \\
(\mathbf{m g} / \mathbf{l})\end{array}$ & $\mathbf{F e}(\mathbf{m g} / \mathbf{l})$ & $\begin{array}{c}\mathbf{C u} \\
(\mathbf{m g} / \mathbf{l})\end{array}$ & $\begin{array}{c}\mathbf{M g} \\
(\mathbf{m g} / \mathbf{l})\end{array}$ & $\begin{array}{c}\text { Mn } \\
(\mathbf{m g} / \mathbf{l})\end{array}$ & $\begin{array}{c}\mathbf{K} \\
(\mathbf{m g} / \mathbf{l})\end{array}$ & $\begin{array}{c}\text { Organic } \\
\text { Content } \\
(\%)\end{array}$ \\
\hline Vinasse & $\begin{array}{c}3.9 \\
4\end{array}$ & 22.3 & 3470 & 106 & 0.18 & 108 & 5.52 & 650 & \\
\hline $\begin{array}{c}\text { Vermicomp } \\
\text { ost }\end{array}$ & $\begin{array}{c}5.2 \\
9\end{array}$ & 102 & 9100 & 5.11 & 0.22 & 10.55 & 40.60 & 6.71 & 5.18 \\
\hline
\end{tabular}

Table 2: Showing the average mass $(\mathrm{g})$ and number of leaves of plants for each treatment in the different experiments

\begin{tabular}{|c|c|c|c|c|c|c|}
\hline Treatments $^{*}$ & \multicolumn{2}{|c|}{ Pakchoi } & \multicolumn{2}{|c|}{ Lettuce } & \multicolumn{2}{|c|}{ Cabbage } \\
\hline & $\begin{array}{l}\text { Average } \\
\text { Mass (g) }\end{array}$ & $S t d^{8}$ & $\begin{array}{l}\text { Average } \\
\text { Mass (g) }\end{array}$ & Std & $\begin{array}{c}\text { Average Mass } \\
\text { (g) }\end{array}$ & Std \\
\hline Control & $269.86^{c}$ & 123.64 & $13.66^{b}$ & 8.48 & $310.85^{\mathrm{a}}$ & 121.03 \\
\hline Vermicompost & $314.25^{D C}$ & 124.61 & $22.34^{\mathrm{a}}$ & 12.49 & $330.79^{a}$ & 172.02 \\
\hline NPK & $372.14^{\text {ab }}$ & 160.00 & $18.70^{\text {ab }}$ & 8.87 & $314.43^{\mathrm{a}}$ & 103.77 \\
\hline Vinasse & $430.02^{\mathrm{a}}$ & 104.00 & $25.40^{\mathrm{a}}$ & 9.94 & $379.36^{a}$ & 136.87 \\
\hline & $\begin{array}{c}\text { Average \# of } \\
\text { leaves }\end{array}$ & Std & $\begin{array}{c}\text { Average \# of } \\
\text { leaves }\end{array}$ & Std & & \\
\hline Control & $11.00^{\mathrm{b}}$ & 3.00 & $7.00^{b}$ & 2.00 & --------- & \\
\hline Vermicompost & $12.00^{\mathrm{ab}}$ & 2.00 & $8.00^{\mathrm{ab}}$ & 2.00 & --------- & \\
\hline NPK & $13.00^{\mathrm{ab}}$ & 4.00 & $7.00^{b}$ & 2.00 & --------- & \\
\hline Vinasse & $13.00^{\mathrm{a}}$ & 3.00 & $9.00^{a}$ & 2.00 & ---------- & \\
\hline
\end{tabular}

$¥$ - indicate the significant differences of the average weight of plants and number of leaves relative to fertilization treatments.

$\S$ - Standard deviation 


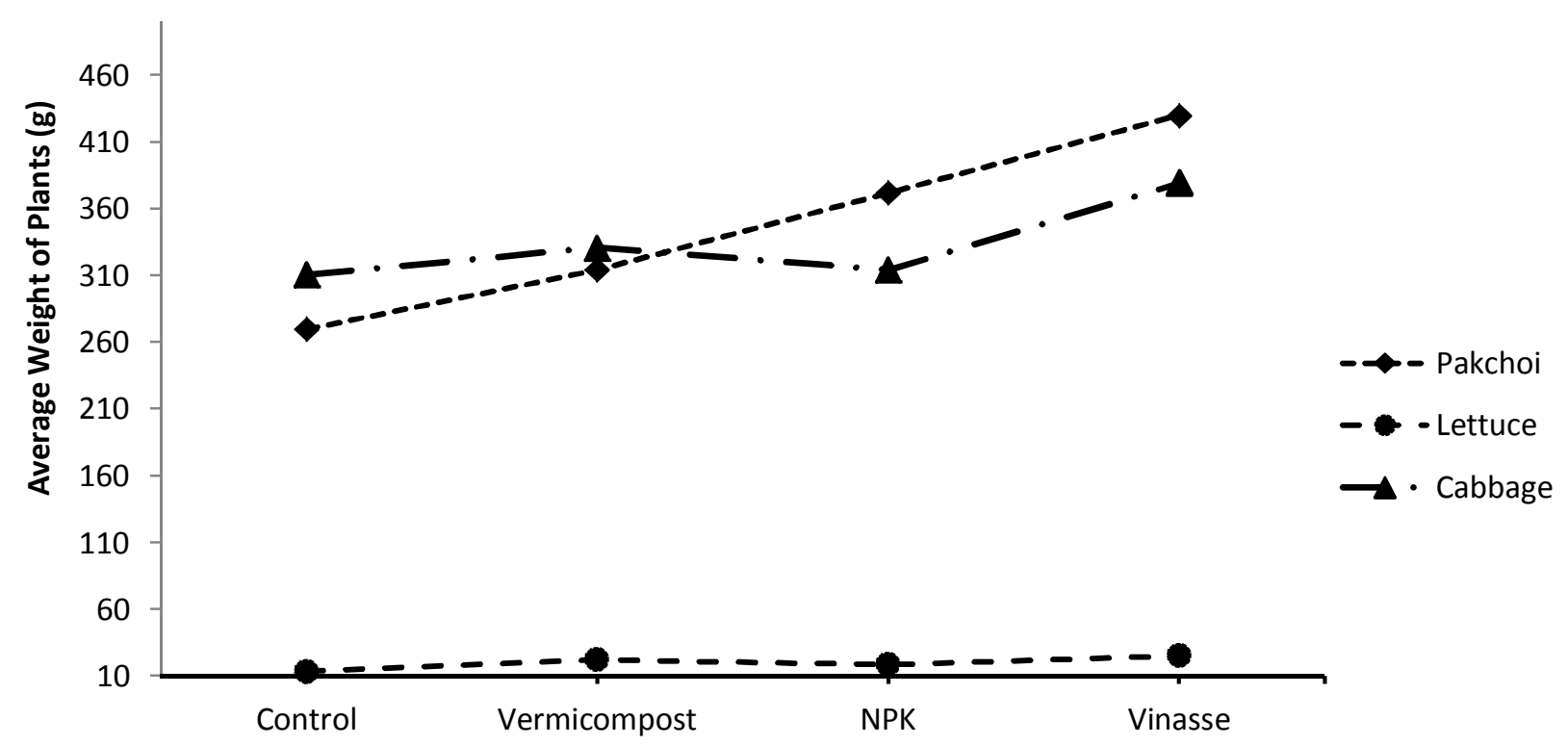

Treatments in Experiment

Figure 1: Line Chart showing the average mass of plants in each treatment for the different crops

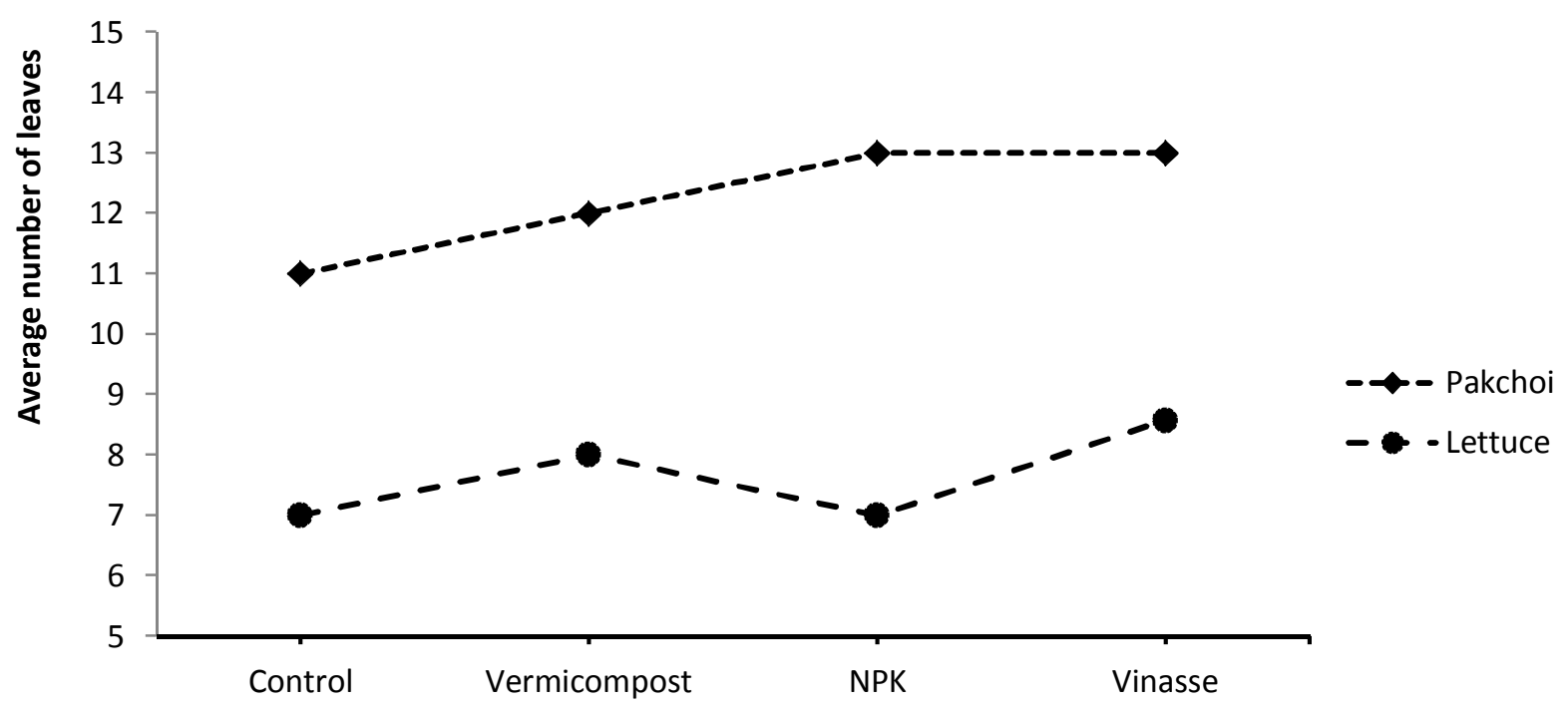

Treatments in Experiment

Figure 2: Line Chart showing the number of leaves in each treatment for the different crop

\section{DISCUSSION}

This study sought to investigate the use of bioethanol effluent (vinasse) and vermicompost as fertilizers for cash crop production by comparing the performance of three cash crops Brassica rappa spp. Chinesis (pakchoi), Lactuca sativa (lettuce) and Brassica oleracea var. capitata (cabbage) when fertilized with vinasse, vermicompost chemical fertilizer or no fertilizer. From this study, crops fertilized with vinasse produced the highest average mass of plant (Table 2) for all the crops evaluated although there was no distinct trend resulting from the fertilization method for all three crops. 
Pakchoi treated with vinasse had the highest average mean mass of $430.02 \mathrm{~g}$, followed by NPK at $372.14 \mathrm{~g}$, vermicompost at $314.25 \mathrm{~g}$ and the control at 269.86g (Figure 1). A similar trend was observed for the number of leaves vinasse (13), NPK (13), vermicompost (12) and control (11), figure 2. Statistical analysis indicate that the average mass of pakchoi plants fertilized with vinasse was significantly different $(p<0.05)$ than those fertilized with vermicompost and those where no fertilizer was applied, and was not significantly different from those fertilized by chemical fertilizer (Table 2). The mean weight of the plants fertilized with NPK and vermicompost were not significantly different. However, this test indicated that the mass of the plants in the control treatment were significantly different from the NPK and the vinasse treated plants but not the vermicompost treatment. Statistical analysis revealed that the mean number of leaves of the vinasse fertilized plants were significantly different $(p<0.05)$ from the control treatment. However, there was no significant difference between vinasse and the plants treated with vermicompost and NPK. On the other hand, the control treatment shows no significant difference between the NPK and vermicompost treatments.

For lettuce, the vinasse treated plants had the greatest average mean mass of $25.40 \mathrm{~g}$, followed by vermicompost at $22.34 \mathrm{~g}$, NPK at $18.70 \mathrm{~g}$ and the control at $13.66 \mathrm{~g}$. With respect to leaf count, a similar trend was observed as the vinasse fertilized beds produced plants with the greatest mean number of leaves being 9, followed by vermicompost with 8 , NPK at 7 and control at 7 (Figure 2). The LSD All Pairwise test noted that the total weight of plants fertilized with vinasse was significantly different $(p<0.05)$ from the control treatment but not the vermicompost and NPK treatments. Furthermore, the NPK treated plants showed no significant difference from the control treatment. Statistical analysis revealed that the mean number of leaves of the vinasse fertilized plants were significantly different $(p<0.05)$ from NPK and the control treatments but not the vermicompost. On the other hand, the test showed that with respect to NPK, vermicompost and the control treatments, there were no significant differences between the mean numbers of leaves.

For cabbage, the data show that the vinasse treated plants produced the highest average mean mass of $379.36 \mathrm{~g}$, followed by vermicompost at $330.79 \mathrm{~g}$, NPK at $314.43 \mathrm{~g}$ and the control at $310.85 \mathrm{~g}$. Statistical analysis indicated that there was no significant difference $(p<0.05)$ in the mean mass amongst the various treatments. Cabbage requires large amounts of nitrogen, phosphorous and potassium during head formation and also has high sulphur and calcium demands. Cabbage also benefits from high organic matter content of soils and is very sensitive to boron and magnesium deficiencies (Pestizid Aktions-Netzwerk, 2015). These properties would make vinasse the most suitable soil amendment for cabbage.

This study has confirmed that both vinasse and vermicompost should be considered as an alternative to synthetic fertilizers in cash crop production locally. This research was focused primarily on leafy vegetable crops of high economic value. In each experiment, vinasse produced the highest yields followed by vermicompost and NPK (Table 2).

Results from other experiments on various crops applying either vinasse or vermicompost have confirmed the potential of using vinasse or vermicompost as fertilizer with comparable or better performance than that of chemical fertilizer. In Thailand, vinasse tested on wheat showed increased nutrient levels in the soil after harvesting while increasing yields. That study noted that the application of vinasse helps in slowing the release of nutrients and organic matter, which aids in increased soil fertility and improved soil structure (Arafat \& Yassen, 2002). Prado et al. (2013) highlighted studies in Brazil and China that noted vinasse as an ideal organic fertilizer that can produce greater yields when the correct application rates are used. In Brazil, using vinasse in sugar cane cultivations showed increased nutrient concentrations in the fields and improved radicular systems of the sugarcane, and in China vinasse resulted generally in increased soil fertility and the presence of residual nutrients in the soil after harvesting. Saranraj and Stella (2012) revealed that both the fresh and dry matter yields of the cowpea were higher when treated with vermicompost. They concurred with Kumaresan et al. (1984) that with the application of vermicompost, various soil nutrients including $\mathrm{P}, \mathrm{N}, \mathrm{Mg}, \mathrm{Ca}$ and $\mathrm{K}$ increased significantly. These studies supports the results of our study and strengthen the notion that vinasse and vermicompost can be used as organic fertilizers suitably replacing chemical fertilizers and increasing yields without adverse environmental effects, thus making them sustainable options. However, further studies are recommended to understand the nutrient release dynamics of these organic fertilizers.

\section{CONCLUSION}

This study was conducted to evaluate the use of vinasse and vermicompost as soil amendments in cash crop production. The experiments were done with crops from the Class of Magnoliopsida, specifically pakchoi, cabbage and lettuce. In addition to the environmental and soil nutrient benefits attained by the use of organic fertilization, vinasse showed the best adaptability for use as fertilizer for cash crops. There was a $35.8 \%, 15.6 \%$ and a $20.7 \%$ higher yield of lettuce, pakchoi and cabbage when vinasse was used as the fertilizer as compared with NPK. With vermicompost there were $19.5 \%$ and $5.2 \%$ higher yields for lettuce and cabbage with a $15.6 \%$ reduction of yield for pakchoi as compared with NPK. This research reinforces the notion that both vinasse and vermicompost contains copious amounts of micro and macron-nutrients that are necessary for plant growth, development and soil fertility enhancement. Further, vinasse and vermicompost can be used as fertilizers for cash crops with greater or 
comparable results as with chemical fertilizers. Therefore given the environmental, and soil and crop nutrient benefits posited by other researchers, it is recommended that chemical fertilizers be replaced by either vinasse or vermicompost as a source of soil amendment in cash crop production.

\section{REFERENCES}

Abrahim, B. N., Clementson, C., and Homenauth, O. 2016. Assessment of the Potential Water Quality Effects Resulting from the Release of Vinasse, from the Bioethanol Demonstration Plant, into the Surrounding Waterway. Greener Journal of Agricultural Sciences 6(3): 102-109.

Aktions-Netzwerk, P. 2015. Cabbage. Retrieved 06 29, 2016, from Online Information Service for NonChemical Pest Management in the Tropics: http://www.oisat.org/crops/vegetables/cabbage.html

Arafat, S., and Yassen, A. E. 2002. Agronomic Evaluation of Fertilizing Efficiency of Vinasse. $17^{\text {th }}$ World Congress of Soil Science, Bangkok, Thailand.

Central Research Institute of Dryland Agriculture. 2016. Vermicompost from Waste. Hyderabad, India. Retrieved $1^{\text {st }} \quad$ September, 2016 from http://compostclub.org/wpcontent/uploads/2010/06/2273.pdf

Diacono, M., and Montemurro, F. 2009. Long-term Effects of Organic Amendments on Soil Fertility: A review. Agronomy for Sustainable Development 30(2):401-422

FAO. 1972. Effects of Intensive Fertilizer Use on the Human Environment. Soils Bulletin 16:360. Rome

Kissel, E. D., Isaac, R.A., Hitchcock, R., Sonon, L. S. and Vendrell, P.F. 2007. Implementation of Soil Lime Requirement by a Single Addition Titration Method. Communications in Soil Science and Analysis 38(9-10):1341-1352.

Kumaresan, M., Manivannan, J., and Karsten, E. R. 1984. Making a high quality compost tea. Biocycle 40(94):22.
Kumari, A., Kumar, R., and Rao, N. 2014. Adverse Effects of Chemical Fertilizers and Pesticides on Human Health and Environment. Journal of Chemical and Pharmaceutical Sciences, Special Issue (3):150-151.

Lazcano, C., and Dominiguez, J. 2011. The Use of Vermicompost in Sustainable Agriculture: Impact on Plant Growth and Soil Fertility. In: Soil Nutrients. Chapter 10. Nova Science Publishers Inc.

Munroe, G. 2016. Manual of On-Farm Vermicomposting and Vermiculture. Organic Agriculture Centre of Canada. Retrieved $1^{\text {st }}$ September 2016 from http://oacc.info/docs/vermiculture_farmersmanual_g m.pdf

National Agricultural Research and Extension Institute. 2016. Green Agriculture- Benefits and Practices. National Agricultural Research and Extension Institute, Georgetown, Guyana.

Palm, C., Myers, R., and Nandwa, S.1997. Combined Use of Organic and Inorganic Nutrient Sources for Soil Fertility Maintenance and Replenishment. American Society of Agronomy and Soil Science Society of America, Special Publication 51(8)193217.

Prado, R., Caione, G., and Campos, C. 2013. Filter Cake and Vinasse as Fertilizers Contributing to Conservation Agriculture. Applied and Environmental Science 2013:1-9.

Saranraj, P., and Stella, D. 2012. Vermicomposting and its Importance in Improvement of Soil Nutrients and Agricultural Crops. Novus Natural Science Research $1(1): 14-23$.

Savci, S. 2012. Investigation of Effect of Chemical Fertilizers on the Environment. Asia-Pacific Chemical, Biological and Environmental Engineering Society Procedia 1(2012):287-292.

Suphachai, A., Takagaki, M., Chaireag, S., Sutevee, S., and Kazuyuki, I. 2006. Effect of Amount of Nitrogen Fertilizer on early Growth of Leafy vegetables in Thailand. Japanese Journal of Tropical Agriculture 50(3):127-132. 